Check for updates

Cite this: J. Mater. Chem. C, 2020 8,6552

Received 7th February 2020, Accepted 1st April 2020

DOI: $10.1039 / \mathrm{d} 0 \mathrm{tc0} 0642 \mathrm{~d}$

rsc.li/materials-c

\title{
Liquid crystalline copper(I) complexes with bright room temperature phosphorescence $\dagger$
}

\begin{abstract}
Raquel Giménez, (DD *a Olga Crespo, ${ }^{\mathrm{b}}$ Beatriz Diosdado ${ }^{\mathrm{b}}$ and Anabel Elduque*b
Phosphorescence in the liquid crystal state with one of the highest quantum yield values, $42 \%$, at room temperature is reported. This property is achieved with cyclic trinuclear copper(1) complexes prepared using 3,5-dimethyl-4-(trialkoxyphenyl)pyrazolate ligands. The compounds show well-organized hexagonal columnar mesophases that are stable at room temperature or near room temperature with intracolumnar order at distances of $3.6 \AA$, red emission and lifetimes consistent with the excimeric metal-centered phosphorescence typical of copper trinuclear pyrazolato complexes. A non-mesogenic analogue shows similar properties, and the single crystal structure is formed by stacked molecules forming a supramolecular extended structure with two different intermolecular $\mathrm{Cu}$...Cu contacts, $3.368 \AA$ and $3.666 \AA$, which are in the range of previously reported weak cuprophilic interactions. The results demonstrate that metallomesogens with efficient room temperature phosphorescence can be obtained with metal complexes other than the widely explored and precious metal-based iridium or platinum complexes.
\end{abstract}

\section{Introduction}

Phosphorescent materials bearing transition metal complexes are intensively investigated for applications in phosphorescent organic light emitting diodes (PhOLEDs). ${ }^{1-3}$ Theoretically, such materials can emit with $100 \%$ internal quantum efficiency due to the possibility of harvesting singlet and triplet excitons, a much higher value than that for fluorescent materials, which only emit through singlet excitons and, therefore, can only reach a theoretical efficiency that is four times smaller. In addition, the large Stokes shift and the long lifetime emission of phosphorescence is advantageous for sensing applications as it avoids interferences from scattered light and short-lived fluorescence. $^{4}$

In the last two decades, the field of luminescent liquid crystalline metal complexes, a particular class of metallomesogens, ${ }^{5}$ has developed significantly. ${ }^{6-8}$ The liquid crystal state offers interesting properties such as the control of the organization and anisotropy combined with better solubility and processing. ${ }^{9}$ Indeed, a controlled orientation of phosphorescent molecules in active

\footnotetext{
${ }^{a}$ Instituto de Ciencia de Materiales de Aragón (ICMA), Departamento de Química Orgánica, Facultad de Ciencias, Universidad de Zaragoza-CSIC, 50009 Zaragoza, Spain. E-mail: raquel.gimenez@ctq.csic.es

${ }^{b}$ Instituto de Sintesis Quimica y Catálisis Homogénea (ISQCH), Departamento de Quimica Inorgánica, Facultad de Ciencias, Universidad de Zaragoza - CSIC,

50009 Zaragoza, Spain

$\dagger$ Electronic supplementary information (ESI) available: Experimental section and additional Tables and Figures. CCDC 1980455. For ESI and crystallographic data in CIF or other electronic format see DOI: 10.1039/d0tc00642d
}

layers has become a crucial topic to improve solid-state emission and efficiency in electronic devices. ${ }^{10}$ The compounds derived from precious heavy metals such as iridium or platinum are the most widely studied with respect to phosphorescence emission. However, the study of the efficiency (quantum yield) in the liquid crystal phase has been largely overlooked. ${ }^{7}$ Nowadays, the goal of attaining low temperature liquid crystals with high emission efficiencies in the liquid crystalline state is fostering the search for new molecules.

Copper(I) complexes have not been widely exploited as luminescent materials in the solid state, ${ }^{11}$ but they have a variety of possible structures and luminescence ranges with great potential. ${ }^{12,13}$ Furthermore, copper is more abundant and is therefore a more affordable alternative to iridium or platinum complexes. With respect to liquid crystalline properties, very few copper(I) metallomesogens have been described and they show a broad structural diversity and varied ligands derived from tetrathiamacrocycles, ${ }^{14}$ diiminobipyridine, ${ }^{15}$ diiminopiridine, ${ }^{16}$ alkylthiolate,${ }^{17}$ terpyridine,${ }^{18}$ isocyanide,${ }^{19-22}$ bis(pyrazolyl)ethyl ether ${ }^{23}$ phenanthroline, ${ }^{24,25}$ pyrazolate, ${ }^{26}$ phosphine, ${ }^{27}$ thiolate, ${ }^{28}$ benzoylthiourea ${ }^{29}$ or biquinoline. ${ }^{30}$ Moreover, the luminescent properties of copper(I) metallomesogens have hardly been analysed ${ }^{26,27,30}$ and only two studies have reported quantum yield measurements, with the maximum values of up to $2.4 \%$ in the columnar phase ${ }^{30}$ or $8 \%$ in the glassy smectic A phase. $^{27}$

In order to obtain efficient copper-based liquid crystalline emitters our attention was focused on cyclic trinuclear complexes (CTCs) with the general structure of $[\mathrm{Cu}(\mu-\mathrm{pz})]_{3}(\mathrm{pz}=$ pyrazolate). 
Copper(I) CTCs show phosphorescence due to emission from a metal-centered triplet state $\left({ }^{3} \mathrm{MM}\right)$ of an excimer, ${ }^{31,32}$ and only very recently has it been reported that very high quantum yields, i.e., over $75 \%$, are affordable in the crystal state at room temperature. ${ }^{33-36}$ Although the planar structure of the metallacycle could facilitate the formation of columnar liquid crystal phases, liquid crystalline behaviour was not observed for copper(I) CTCs even on using the same ligands as those used for liquid crystalline silver(I) and gold(I) CTCs. ${ }^{34}$ For example, silver(I) and gold(I) complexes with the 4-hexyl-3,5-dimethylpyrazolate ligand are liquid crystalline, but the copper(I) complex has a lower melting point and exhibits direct transition to the isotropic liquid. This behaviour has been attributed to weaker metallophilic interactions. To our knowledge, there is only one study that has reported about liquid crystallinity in copper(I) CTCs, and this was concerned with complex dendritic pyrazolate ligands. A columnar mesophase was claimed; however, its appearance required an aging process to develop the material without crystallization and the quantum yield value was not measured. ${ }^{26}$

Based on the above precedents showcasing great potential for research on novel copper(I) phosphorescent metallomesogens we carried out our study with the following aims: (1) to obtain a stable and well-organized liquid crystalline phase for copper(I) CTCs using structurally simple ligands, (2) to stabilize the mesophase at room temperature or near room temperature, and (3) to obtain bright phosphorescence at room temperature in the liquid crystal state. We report here the synthesis and characterisation of these novel compounds (Scheme 1) along with the study of the mesophases and their luminescent properties.

\section{Results and discussion}

\section{Synthesis and single crystal structure of $\mathrm{Cu1}$}

Two copper complexes with a total of nine long alkoxy chains, Cu10 and Cu14, were prepared from 3,5-dimethyl-4-trialkoxyphenylpyrazoles. ${ }^{37}$ By adapting a synthetic procedure, ${ }^{38}$ triethylamine was mixed with the pyrazole ligand in acetone and then reacted with $\left[\mathrm{Cu}\left(\mathrm{CH}_{3} \mathrm{CN}\right)_{4}\right] \mathrm{BF}_{4}$ to yield the trinuclear

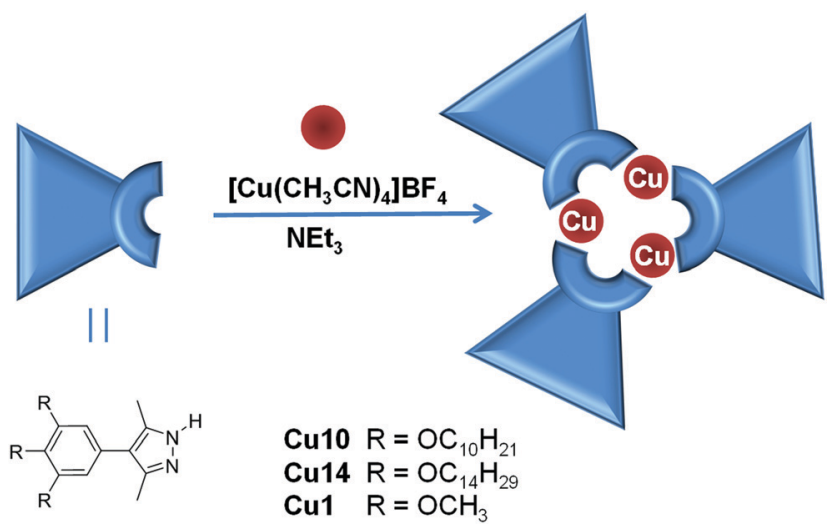

Scheme 1 Illustration of the copper complexes described in this work and their synthetic procedure. complex (Scheme 1). Experimental details and characterisation data are provided in the ESI, $\dagger$ and the data are consistent with the expected trinuclear stoichoimetry.

An analogous compound with nine methoxy substituents, Cu1, was synthesized under the same reaction conditions. Long colourless needles were obtained by slow diffusion of hexane into a concentrated solution of the compound in dichloromethane at room temperature. Albeit the needles were unstable during manipulation, it was possible to obtain structural information about $\mathbf{C u 1} \cdot \mathbf{C H}_{2} \mathbf{C l}_{2}$. Details of data collection and refinement are shown in Table $\mathrm{S} 1$ (ESI $\dagger$ ).

Cu1. $\mathbf{C H}_{2} \mathbf{C l}_{2}$ crystallised in the monoclinic space group $P 2_{1} / n$. The unit cell contains four molecules of $\mathbf{C u 1}$ and four molecules of dichloromethane near the peripheral methoxy groups. The crystal structure confirms the trinuclear stoichoimetry of the complex (Fig. 1a and b), which consists of an almost flat metallacycle core formed by the three pyrazolate rings and the three copper atoms. The values of the $\mathrm{N}-\mathrm{Cu}(1.865-$ $1.846 \AA$ A) and intramolecular $\mathrm{Cu}$. . Cu distances (3.185-3.226 ̊) are in agreement with those found for reported copper(I) complexes derived from 3,5-dimethylpyrazolates, ${ }^{35,39-41}$ with $\mathrm{N}-\mathrm{Cu}-\mathrm{N}$ angles close to the ideal linear coordination (177.4-179.8 ${ }^{\circ}$. All phenyl rings located at the 4-position of the pyrazolate rings do not have the same disposition; one of them is coplanar with the metallacycle whereas the other two are twisted by $40^{\circ}$ and $56^{\circ}$ (Fig. 1c). This lack of planarity has been previously documented to occur in a variable range of $33-76^{\circ}$ but in all these structures the three phenyl substituents were out of plane. ${ }^{42-44}$

As far as the crystal packing is concerned, the main structural characteristic of $\mathbf{C u 1}$ is that the molecules are stacked along the $b$ axis (Fig. 1b). The $b$ axis and the normal to the average molecular plane make an angle of $c a .24^{\circ}$, therefore the molecules are tilted inside the stack, with alternating sense in the nearest stacks. Inside each stack the molecules are arranged in a slipped antiparallel fashion. In such a way the pyrazolate ligands spread around the columnar axis. The shortest $\mathrm{Cu} \cdot \mathrm{Cu}$ intermolecular distances measured between closest neighbours alternate between $3.368 \AA\left(\mathrm{Cu}(1) \cdots \mathrm{Cu}\left(2^{\prime}\right)\right)$ and $3.666 \AA\left(\mathrm{Cu}(1) \cdots \mathrm{Cu}\left(3^{\prime \prime}\right)\right)$. Based on previous reports that use a re-evaluated van der Waals radius of $1.92 \AA{ }^{12}$ these $\mathrm{Cu} \cdots \mathrm{Cu}$ distances lie in the range of weak intermolecular cuprophilic interactions (attractive interactions between closed shell $\mathrm{d}^{10}$ copper(I) atoms), although this assumption is made here without evidence of real attractive interactions. Considering these values, and in similarity to previous reports, ${ }^{41}$ a supramolecular extended structure is formed along the stack in which each molecule establishes two contacts at distances of $3.368 \AA$ with one neighbour, and two contacts at distances of $3.666 \AA$ with the other neighbour, with one copper atom engaged in two interactions (Fig. 1d).

\section{Liquid crystalline properties}

Complexes Cu10 and Cu14 show thermodynamically stable liquid crystal phases. The results obtained from the optical and thermal studies are presented in Table 1 along with the XRD data for the mesophases. Textures observed between crossed polarisers using 

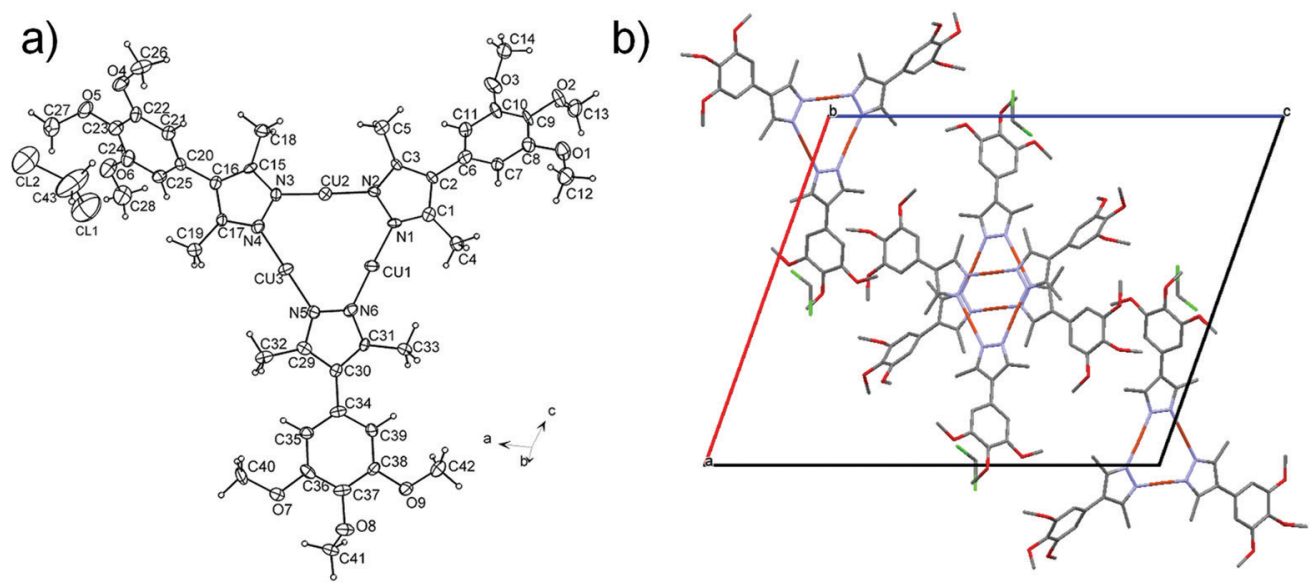

c)

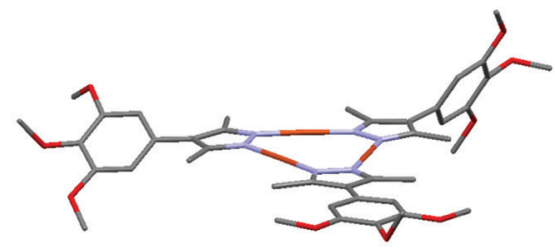

d)

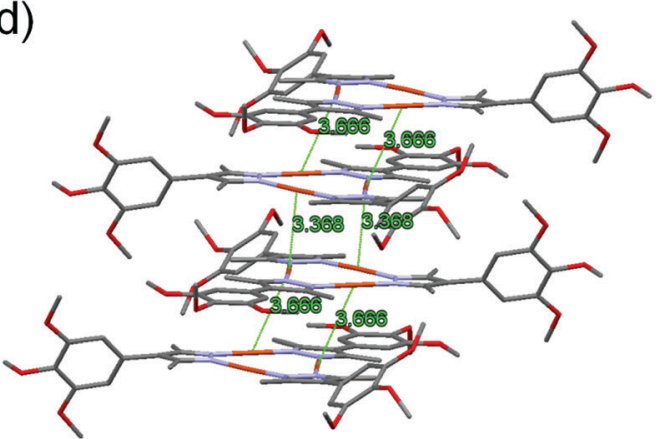

Fig. 1 Cu1. $\mathrm{CH}_{2} \mathrm{Cl}_{2}$ single crystal structure. (a) ORTEP drawing with atom numbering (elipsoids at $50 \%$ ). (b) Unit cell view along the $b$ axis. (c) Side view of one molecule. (d) Stacking of four molecules in a column with the shortest intermolecular $\mathrm{Cu}$...Cu distances indicated in green color.

an optical microscope show focal-conic and dendritic defects that are typical of columnar mesophases (Fig. 2a and b).

Control of the mesophase stability and temperatures is achieved by varying the length of the alkoxy chains. A chain with a length of 10 carbon atoms stabilises the mesophase over a wider range of temperatures, e.g., $\mathbf{C u 1 0}$ has a higher clearing point and a lower melting point with respect to $\mathbf{C u 1 4}$, which means that the mesophase is stable over a range of $108{ }^{\circ} \mathrm{C}$ on heating from $20^{\circ} \mathrm{C}$ and remains in the mesophase down to $8{ }^{\circ} \mathrm{C}$ in the cooling cycle (Fig. 2c).

XRD patterns of the liquid crystal phase show a rich set of sharp reflections in the small angle region, up to seven for Cu10, that are in a ratio of $1:(1 / \sqrt{ } 3):(1 / \sqrt{ } 4):(1 / \sqrt{ } 7):(1 / \sqrt{ } 9):$ $(1 / \sqrt{ } 12):(1 / \sqrt{ } 13)$ and are indexed to a $2 \mathrm{D}$ hexagonal lattice (Table 1 and Fig. 2d). This aspect also indicates a long-range correlation of the 2D arrangement of the columns. In the wideangle region a broad reflection was observed at a distance of around 4.5 $\AA$. This reflection corresponds to the diffuse halo typical of the liquid crystalline state owing to the fluctuations of the molten chains. All this information allowed us to unambiguously assign the liquid crystal phase to a hexagonal columnar mesophase. In addition to the above, an intense and sharp reflection was observed at $3.6 \AA$ and this indicates a periodicity of the molecules within the columns (intracolumnar order) that extends over quite large distances. A similar behavior was observed for Cu14 (Fig. S1, ESI $\dagger$ ), albeit with larger lattice parameters because of the longer peripheral side chains.
Table 1 Characterization data for the liquid crystal phases

\begin{tabular}{|c|c|c|c|c|}
\hline & $\begin{array}{l}\text { Phase transition }{ }^{a} \\
T /{ }^{\circ} \mathrm{C}\left(\Delta H / \mathrm{kJ} \mathrm{mol}^{-1}\right)\end{array}$ & $d^{b} / \AA$ & $\begin{array}{l}\text { Miller } \\
\text { index }\end{array}$ & $\begin{array}{l}\text { Mesophase } \\
\text { parameters/A }\end{array}$ \\
\hline Cu10 & $\begin{array}{l}\text { Cr } 20(34.7) \mathrm{Col}_{\mathrm{h}} 128(15.4) \mathrm{Iso} \\
\text { Iso } 127(17.9) \mathrm{Col}_{\mathrm{h}} 8(44.8) \mathrm{Cr}\end{array}$ & $\begin{array}{l}29.0 \\
16.8 \\
14.5 \\
10.9 \\
9.7 \\
8.3 \\
8.1 \\
4.5 \text { (br) } \\
3.6\end{array}$ & $\begin{array}{l}10 \\
11 \\
20 \\
21 \\
30 \\
22 \\
31\end{array}$ & $\begin{array}{l}\mathrm{Col}_{\mathrm{h}} \\
a=33.5 \\
c=3.6\end{array}$ \\
\hline Cu14 & $\begin{array}{l}\mathrm{Cr} 43(57.5) \mathrm{Col}_{\mathrm{h}} 100 \text { (7.1) Iso } \\
\text { Iso } 98(10.5) \mathrm{Col}_{\mathrm{h}} 34(94.0) \mathrm{Cr}\end{array}$ & $\begin{array}{l}33.6 \\
19.5 \\
16.7 \\
12.5 \\
11.2 \\
4.5 \text { (br) } \\
3.6\end{array}$ & $\begin{array}{l}10 \\
11 \\
20 \\
21 \\
30\end{array}$ & $\begin{array}{l}\mathrm{Col}_{\mathrm{h}} \\
a=38.8 \\
c=3.6\end{array}$ \\
\hline
\end{tabular}

${ }^{a}$ DSC data at $10{ }^{\circ} \mathrm{C} \mathrm{min}^{-1}$, onset temperatures, Cr: crystal phase, $\mathrm{Col}_{\mathrm{h}}$ : hexagonal columnar mesophase, Iso: isotropic liquid. ${ }^{b}$ Distances from the X-ray diffractograms of the mesophases measured on heating at $40{ }^{\circ} \mathrm{C}$ for $\mathrm{Cu} 10$ and at $55{ }^{\circ} \mathrm{C}$ for $\mathrm{Cu} 14$.

A self-assembly model can be proposed by estimating the number of molecules $Z$ in a columnar stratum of thickness $c$. The volume of the columnar stratum of thickness $c$ can be calculated from X-ray data to be $V_{\text {cell }}=c S_{\text {col }}$, where $c=3.6 \AA$, is the stacking periodicity, and $S_{\text {col }}$ is the columnar cross-section 


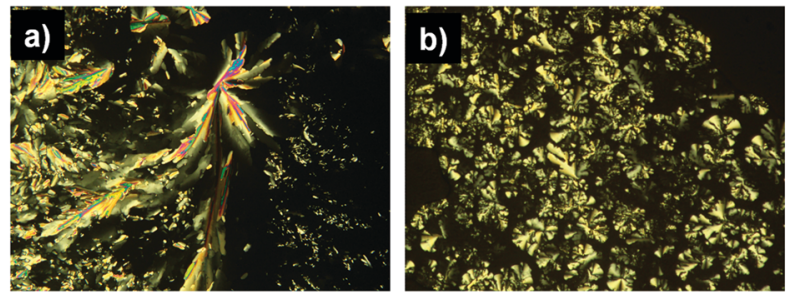

c)
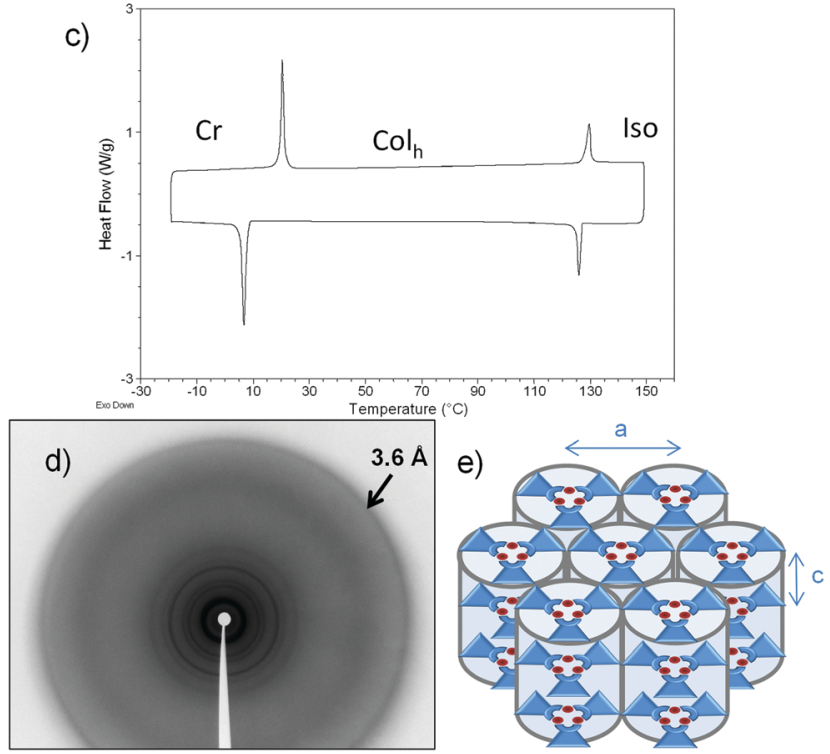

Fig. 2 (a) Microphotograph of the region between crossed polarisers observed for the texture of the $\mathrm{Col}_{\mathrm{h}}$ phase of Cu10 on cooling the isotropic liquid at $126^{\circ} \mathrm{C}$. (b) The same for Cu14 on cooling the isotropic liquid at $98^{\circ} \mathrm{C}$. (c) DSC thermogram of Cu10. (d) XRD patterns of the Colh phase of Cu10. The arrow indicates the halo corresponding to the stacking distance. (e) Self-assembly in the hexagonal columnar mesophase.

of the hexagonal lattice $\left(S_{\mathrm{col}}=a^{2} \sqrt{ } 3 / 2\right)$. The $Z$ value is then obtained from the equation $V_{\text {cell }}=Z V_{\mathrm{m}}$, where $V_{\mathrm{m}}$ is the molecular volume. Considering a density of $1 \mathrm{~g} \mathrm{~cm}^{-3}$ in the mesophase, the molecular volume can be calculated as $V_{\mathrm{m}}=$ $M / 0.6022$, where $M$ is the molecular weight. From these equations $Z$ values of 1.0 and 1.08 are obtained for $\mathbf{C u 1 0}$ and Cu14, respectively.

Therefore, both compounds self-assemble into columns that are arranged in a very well-organized 2D hexagonal network with a single molecule stacked along this column (Fig. 2e). In addition, the stacking distance of $c=3.6 \AA$ along the column could also be compatible with weak intermolecular cuprophilic interactions, similar to those observed in the single crystal structure of $\mathbf{C u 1}$, and this is reflected in the photoluminescence properties (see below).

\section{Photoluminescence properties}

The emission properties of the complexes were studied by preparing neat thin films on quartz plates. Both Cu10 and Cu14 showed orange-red coloured emissions at room temperature and the photoluminescence spectra exhibited a broad band centred at around 661-664 nm (Fig. 3 and Fig. S2, ESI $\dagger$ ). A lifetime of 26-28 microseconds with a monoexponential

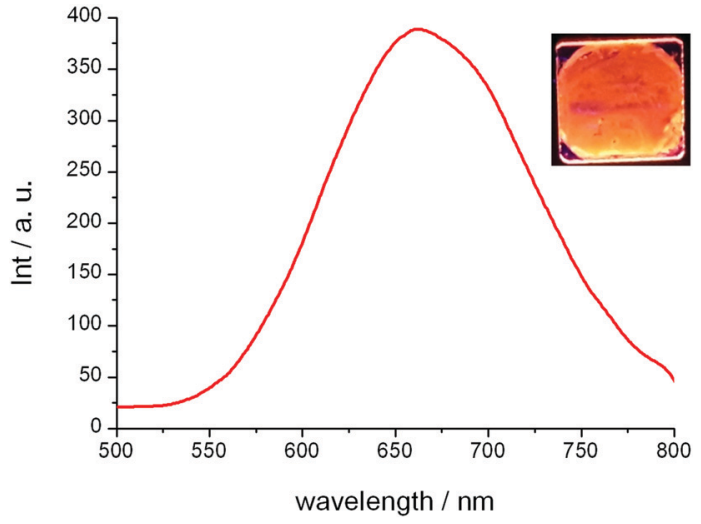

Fig. 3 Photoluminescence spectrum in the columnar mesophase for Cu10 at $25{ }^{\circ} \mathrm{C}$ (excitation wavelength $290 \mathrm{~nm}$ ), and emission of the film observed under irradiation with a $254 \mathrm{~nm}$ handheld lamp (overexposed picture, exact color is given by CIE 1931 color space coordinates in Table 2).

decay was measured at room temperature. This fact and a large Stokes shift are consistent with phosphorescence (Table 2 and Fig. S3, S4, ESI $\dagger$ ).

It is interesting to note that Cu10 and Cu14 show similar behaviour even though the measurements at room temperature were performed in different phases, the liquid crystal state for Cu10 and the crystal phase for Cu14. To further confirm this similarity, photoluminescence spectrum and lifetime were measured at $50{ }^{\circ} \mathrm{C}$ for $\mathbf{C u 1 4}$, i.e., a temperature at which the compound is in the same liquid crystal state as Cu10. Emission wavelength remained unchanged and only a decrease of the emission intensity as shown in Fig. S5 (ESI†), and a slight decrease of lifetime were observed as consequence of the increased temperature (Fig. S3, ESI $\dagger$ ). Decrease of the emission intensity, as shown in Fig. S5 (ESI $\dagger$ ) is, of course, not quantitative. As the quantum yield at $50{ }^{\circ} \mathrm{C}$ could not be measured, the real effect of temperature in $k_{\mathrm{nr}}$ may not be discussed, although data could point to a small increment.

Cu1 also shows similar behaviour to the liquid crystalline compounds in color coordinates and emission maxima, albeit with a bi-exponential decay. The decay experiment allows to calculate the intensity averaged lifetime, and this is slightly shorter than for the liquid crystalline compounds. Quenching processes may be not simple and calculated averaged lifetimes (intensity- or amplitude-) and constant $k_{\mathrm{r}}$ and $k_{\mathrm{nr}}$ values must be interpreted with care (Table 2 and Fig. S6, ESI $\dagger$ ). ${ }^{45,46}$

The obtained spectra and lifetimes are consistent with an excimer ${ }^{3} \mathrm{MM}$ centred emission of cofacially arranged molecules described for crystalline $\mathrm{Cu}$ CTCs, ${ }^{31,32}$ and in accordance with the self-assembly proposed for the liquid crystal phase and the XRD structure of Cu1. Indeed, the emission spectra of isolated molecules (in dilute THF solutions) are quite different, with only one band in the UV-A region at $356-359 \mathrm{~nm}$ (Fig. S7, ESI $\dagger$ ), which is similar to the emission shown by the $1 H$-pyrazole precursors. ${ }^{37}$

For compound $\mathbf{C u 1 0}$, the emission measured at $25{ }^{\circ} \mathrm{C}$ corresponds to the hexagonal columnar mesophase. Remarkably, a high QY value, $42 \%$, was measured in the liquid crystalline 
Table 2 Luminescence data of neat thin films

\begin{tabular}{|c|c|c|c|c|c|c|c|}
\hline & Phase $\left(T /{ }^{\circ} \mathrm{C}\right)$ & $\lambda_{\mathrm{em}}{ }^{a} / \mathrm{nm}$ & $\tau / \mu \mathrm{s}$ & $\mathrm{QY}^{a d} / \%$ & $k_{\mathrm{r}}^{e} / \mathrm{s}^{-1}$ & $k_{\mathrm{nr}}^{e} / \mathrm{s}^{-1}$ & CIE $1931\left(2^{\circ}\right)$ coordinates $(x, y)$ \\
\hline $\mathrm{Cu10}$ & $\mathrm{Col}_{\mathrm{h}}\left(25^{\circ} \mathrm{C}\right)$ & 661 & $28(0.999)^{b}$ & 42 & $15.0 \times 10^{3}$ & $20.7 \times 10^{3}$ & $(0.61,0.36)$ \\
\hline Cu14 & $\mathrm{Cr}\left(25^{\circ} \mathrm{C}\right)$ & 664 & $26(0.999)^{b}$ & 14 & $5.4 \times 10^{3}$ & $33.1 \times 10^{3}$ & $(0.60,0.36)$ \\
\hline Cu14 & $\mathrm{Col}_{\mathrm{h}}\left(50{ }^{\circ} \mathrm{C}\right)$ & 664 & $22(0.999)^{b}$ & - & - & - & - \\
\hline Cu1 & $\mathrm{Cr}\left(25^{\circ} \mathrm{C}\right)$ & 663 & $21(0.996)^{b c}$ & 24 & $11.4 \times 10^{3}$ & $36.2 \times 10^{3}$ & $(0.61,0.36)$ \\
\hline
\end{tabular}

${ }^{a}$ Excitation wavelength of $290 \mathrm{~nm}$, excitation spectra collected in Fig. S4 (ESI). ${ }^{b}$ Goodness of fit. ${ }^{c}$ Fitted to the second exponential function. Intensity-averaged lifetime: $\langle\tau\rangle=\left[B_{1} \tau_{1}{ }^{2}+B_{2} \tau_{2}{ }^{2}\right] /\left[B_{1} \tau_{1}+B_{2} \tau_{2}\right]^{45,46}$ (see ESI: $B_{1}=1344.195 ; \tau_{1}=6.34 \times 10^{-6} ; B_{2}=3279.177 ; \tau_{2}=2.23 \times 10^{-5}$ ). ${ }^{d}$ Absolute QY measurement only possible at RT. Standard deviations calculated for Cu1 (1.9), Cu10 (0.8), and Cu14 (0.7). ${ }^{e}$ Calculated radiative constant $\left(k_{\mathrm{r}}=\mathrm{QY} / \tau\right)$ and non-radiative constant $\left(k_{\mathrm{nr}}=(1-\mathrm{QY}) / \tau\right)$.

state, the highest value reported for a copper metallomesogen, and surpassing the QY values obtained for the scarce number of phosphorescent complexes measured in the liquid crystal phase. $^{7}$ Notably, this value is also higher than the ones obtained for the crystalline states of Cu14 and Cu1.

The high QY of Cu10 is favoured by a higher radiative constant and a lower non-radiative constant than that of Cu14. The radiative constant value is comparable to previously reported ones for copper(I) pyrazolates. ${ }^{36}$

\section{Conclusions}

A novel luminescent copper(I) metallomesogen that shows phosphorescence in the liquid crystalline state with a quantum yield of $42 \%$ at room temperature is reported.

3,5-Dimethyl-4-(trialkoxyphenyl)pyrazolate ligands enable the arrangement of copper(I) CTCs in a well-organized 2D hexagonal network of columns, in which the molecules are stacked with a high degree of intracolumnar order compatible with weak cuprophilic intermolecular interactions. This supramolecular organization of cofacially assembled molecules at distances of $3.6 \AA$ in the liquid crystal phase is capable of providing the red emission derived from excimer-like ${ }^{3} \mathrm{MM}$ transitions.

Within the copper metallacycles, it is possible to control the mesophase temperature ranges by tuning the terminal chain substitution.

These results show that room temperature bright phosphorescent metallomesogens can be attained using earth-abundant non-precious copper complexes, thus widening the prospects for the application of metallomesogens as efficient emissive materials.

\section{Conflicts of interest}

There are no conflicts to declare.

\section{Acknowledgements}

This work was financially supported by the FEDER/MICIU-AEI/ projects PGC2018-093761-B-C31 and CTQ2017-83421-P, FEDER/ MINECO/project CTQ2016-75816-C2-1-P, and the Gobierno de Aragón/FEDER (research groups E47_17R, E07_17R and E08_17R). The authors acknowledge the use of Servicios Científico-Técnicos of CEQMA (UZ-CSIC). We acknowledge support of the publication fee by the CSIC Open Access Publication Support Initiative through its Unit of Information Resources for Research (URICI).

\section{Notes and references}

1 H. Xu, R. Chen, Q. Sun, W. Lai, Q. Su, W. Huang and X. Liu, Chem. Soc. Rev., 2014, 43, 3259-3302.

2 K. Li, G. S. Ming Tong, Q. Wan, G. Cheng, W.-Y. Tong, W.-H. Ang, W.-L. Kwong and C.-M. Che, Chem. Sci., 2016, 7, 1653-1673.

3 L. Xiao, Z. Chen, B. Qu, J. Luo, S. Kong, Q. Gong and J. Kido, Adv. Mater., 2011, 23, 926-952.

4 Q. Zhao, F. Li and C. Huang, Chem. Soc. Rev., 2010, 39, 3007-3030.

5 D. Pucci and B. Donnio, in Handbook of Liquid Crystals, ed. J. W. Goodby, P. J. Collings, K. Kato, C. Tschierske, H. Gleeson and P. Raynes, Wiley-VCH, Weinheim, 2014, vol. 5, ch. 4, pp. 1-67.

6 K. Binnemans, J. Mater. Chem., 2009, 19, 448-453.

7 X. Wu, M. Zhu, D. W. Bruce, W. Zhu and Y. Wang, J. Mater. Chem. C, 2018, 6, 9848-9860.

8 Y. Wang, J. Shi, J. Chen, W. Zhu and E. Baranoff, J. Mater. Chem. C, 2015, 3, 7993-8005.

9 M. O'Neill and S. M. Kelly, Adv. Mater., 2011, 23, 566-584.

10 J. Kim, T. Batagoda, J. Lee, D. Sylvinson, K. Ding, P. J. G. Saris, U. Kaipa, I. W. H. Oswald, M. A. Omary, M. E. Thompson and S. R. Forrest, Adv. Mater., 2019, 1900921.

11 V. W.-W. Yam, V. K.-M. Au and S. Y.-L. Leung, Chem. Rev., 2015, 115, 7589-7728.

12 E. Cariati, E. Lucenti, C. Botta, U. Giovanella, D. Marinotto and S. Righetto, Coord. Chem. Rev., 2016, 306, 566-614.

13 F. Dumur, Org. Electron., 2015, 21, 27-39.

14 F. Neve, M. Ghedini, A. M. Levelut and O. Francescangeli, Chem. Mater., 1994, 6, 70-76.

15 A. El-ghayoury, L. Douce, A. Skoulios and R. Ziessel, Angew. Chem., Int. Ed., 1998, 37, 2205-2208.

16 L. Douce, A. El-ghayoury, R. Ziessel and A. Skoulios, Chem. Commun., 1999, 2033-2034.

17 P. Espinet, M. C. Lequerica and J. M. Martín-Alvarez, Chem. - Eur. J., 1999, 5, 1982-1986.

18 R. Ziessel, L. Douce, A. El-ghayoury, A. Harriman and A. Skoulios, Angew. Chem., Int. Ed., 2000, 39, 1489-1493. 
19 M. Benouazzane, S. Coco, P. Espinet and J. Barberá, J. Mater. Chem., 2001, 11, 1740-1744.

20 M. Benouazzane, S. Coco, P. Espinet and J. Barberá, Inorg. Chem., 2002, 41, 5754-5759.

21 S. Coco, C. Cordovilla, B. Donnio, P. Espinet, M. J. GarcíaCasas and D. Guillon, Chem. - Eur. J., 2008, 14, 3544-3552.

22 R. Dembinski, P. Espinet, S. Lentijo, M. W. Markowicz, J. M. Martín-Alvarez, A. L. Rheingold, D. J. Schmidt and A. Sniady, Eur. J. Inorg. Chem., 2008, 1565-1572.

23 H.-D. Lin and C. K. Lai, Dalton Trans., 2001, 2383-2387.

24 R. Ziessel, G. Pickaert, F. Camerel, B. Donnio, D. Guillon, M. Cesario and T. Prangé, J. Am. Chem. Soc., 2004, 126, 12403-12413.

25 E. D. Baranoff, J. Voignier, T. Yasuda, V. Heitz, J. P. Sauvage and T. Kato, Angew. Chem., Int. Ed., 2007, 46, 4680-4683.

26 A. Kishimura, T. Yamashita, K. Yamaguchi and T. Aida, Nat. Mater., 2005, 4, 546-549.

27 B. Huitorel, Q. Benito, A. Fargues, A. Garcia, T. Gacoin, J. P. Boilot, S. Perruchas and F. Camerel, Chem. Mater., 2016, 28, 8190-8200.

28 J. Duan, L. Liu, Z. Wu, J. Fang and D. Chen, CrystEngComm, 2018, 20, 4025-4035.

29 M. Iliş and V. Cîrcu, J. Chem., 2018, 2018, 7943763.

30 C. Cretu, A. A. Andelescu, A. Candreva, A. Crispini, E. I. Szerb and M. La Deda, J. Mater. Chem. C, 2018, 6, 10073-10082.

31 I. I. Vorontsov, A. Y. Kovalevsky, Y.-S. Chen, T. Graber, M. Gembicky, I. V. Novozhilova, M. A. Omary and P. Coppens, Phys. Rev. Lett., 2005, 94, 193003.

32 M. A. Omary, M. A. Rawashdeh-Omary, M. W. A. Gonser, O. Elbjeirami, T. Grimes and T. R. Cundari, Inorg. Chem., 2005, 44, 8200-8210.
33 R. Galassi, M. M. Ghimire, B. M. Otten, S. Ricci, R. N. McDougald, R. M. Almotawa, D. Alhmoud, J. F. Ivy, A.-M. M. Rawashdeh, V. N. Nesterov, E. W. Reinheimer, L. M. Daniels, A. Burini and M. A. Omary, Proc. Natl. Acad. Sci. U. S. A., 2017, 114, E5042.

34 J. Cored, O. Crespo, J. L. Serrano, A. Elduque and R. Giménez, Inorg. Chem., 2018, 57, 12632-12640.

35 Y. Zhang, H. Zhang and J. Xiang, Z. Anorg. Allg. Chem., 2016, 642, 1173-1177.

36 H. Yang, J. Zheng, S.-K. Peng, X.-W. Zhu, M.-Y. Wan, W. Lu and D. Li, Chem. Commun., 2019, 55, 4635-4638.

37 H. Blanco, V. Iguarbe, J. Barberá, J. L. Serrano, A. Elduque and R. Giménez, Chem. - Eur. J., 2016, 22, 4924-4930.

38 G. La Monica and G. A. Ardizzoia, Inorg. Synth., 1997, 31, 299-302.

39 M. K. Ehlert, S. J. Rettig, A. Storr, R. C. Thompson and J. Trotter, Can. J. Chem., 1990, 68, 1444-1449.

40 M. K. Ehlert, S. J. Rettig, A. Storr, R. C. Thompson and J. Trotter, Can. J. Chem., 1992, 70, 2161-2173.

41 H. V. R. Dias, H. V. K. Diyabalanage, M. G. Eldabaja, O. Elbjeirami, M. A. Rawashdeh-Omary and M. A. Omary, J. Am. Chem. Soc., 2005, 127, 7489-7501.

42 Q. Xiao, J. Zheng, M. Li, S.-Z. Zhan, J.-H. Wang and D. Li, Inorg. Chem., 2014, 53, 11604-11615.

43 F. Gong, Q. Wang, J. Chen, Z. Yang, M. Liu, S. Li, G. Yang, L. Bai, J. Liu and Y. Dong, Inorg. Chem., 2010, 49, 1658-1666.

44 X.-L. Wang, J. Zheng, M. Li, S. Weng Ng, S. L.-F. Chan and D. Li, Cryst. Growth Des., 2016, 16, 4991-4998.

45 J. R. Lakowicz, Principles of Fluorescence Spectroscopy, Springer, US, 3rd edn, 2006.

46 B. Valeur and M. N. Berberan-Santos, Molecular Fluorescence: Principles and Applications, Wiley-VCH, 2013. 